\title{
Constriction Ring Syndrome
}

\author{
Jaya Pradha Dhandapani ${ }^{1}$, Venkateshvaran Ponnusamy ${ }^{2}$
}

\begin{abstract}
The inborn constriction ring syndrome (CRS) encloses collective anomalies that develop in various amalgamation, typically damaging the lower extremities (limbs) and hardly the head as well as trunk. This syndrome has an inherited limb deformities. These anomalies with a variety of diagnostic presentations were described by showing the partial to complete, inherit, fibrous, circumferential, constriction bands or rings on any parts of the body, even though a particular predilection for both upper and lower extremities is visible. The CRS incidence differs from one case in 1500-15,000 live births. Eighty percent of cases happen in digits and upper extremities. More than $90 \%$ presents in the region of distal to wrist area. The familial ratio is relatively low, and it is thought that there is no inborn involuntary component to this disease. The diagnostic measures regarding the CRS can be authenticated with the help of ultrasonography. The clinical features may be totally different, and also, it could be due to one or more manifestations. This can be validated at the end of the first trimester or at the beginning of the second trimester. The treatment commonly follows after birth and where plastic and reconstructive surgery is believed to treat the resulting deformation. Plastic surgery was classified from simple to complex based on the extent of the deformity. Physical and occupational therapy may be necessary for a prolonged period. Amniotic band syndrome is considered an accidental event, and it does not appear to be genetic or hereditary, so the likelihood of it occurring in another pregnancy is distant. The reason for amnion tearing is not known, and as such, there are no known prophylactic measures. Congenital CRS is of unknown etiology and can lead to morbidity in the newborn. The syndrome and its complications are controllable with corrective surgery with good outcomes. Early intervention is agreeable for successful results.
\end{abstract}

Keywords: Abnormalities, Congenital, Constriction ring syndrome, Malformation.

Pondicherry Journal of Nursing (2021): 10.5005/jp-journals-10084-13104

\section{INTRODUCTION}

The inborn constriction ring syndrome (CRS) encloses collective anomalies that develop in various amalgamation, typically damaging the lower extremities (limbs) and hardly the head as well as trunk. ${ }^{1}$ It is interrelated with fibrous bands that encircle, strangle, and even remove some parts of the fetus. Amniotic band syndrome happens when loose fibrous bands of amnion rupture attach to and implicate the normal growing structures of the fetus. ${ }^{2}$ It is also otherwise called as amniotic disruption sequence, annular band, CRS, premature amnion rupture sequence, Streeter's dysplasia, intrauterine or congenital amputations, acrosyndactyly, and fenestrated syndactyly. ${ }^{3}$

\section{Definition}

The inborn CRS is an inherited limb deformity, and it encloses anomalies with a variety of diagnostic presentations described showing the partial to complete, inherit, fibrous, circumferential, constriction bands or rings on any parts of the body, even though a peculiar predilection for both upper and lower extremities is visible. ${ }^{4}$ Phenotypes that differ from only a mild skin incision to whole parts also can be removed from the fetus (e.g., digits and distal limb). Pressure from the rings may cause edema, skeletal anomalies (e.g., fractures and foot deformities), and, less often, neural compromise. ${ }^{5}$

\section{INCIDENCE}

The CRS incidence differs from one case in 1500-15,000 live births. Eighty percent of cases happen in digits and upper extremities. More than $90 \%$ presents in the region of distal to the wrist area. Familial ratio is very minimal, and it is considered that there is no inborn involuntarily to this syndrome. ${ }^{6}$
${ }^{1}$ Department of Obstetrics and Gynecological Nursing, Kasturba Gandhi Nursing College, Sri Balaji Vidyapeeth (Deemed to be University), Puducherry, India

${ }^{2}$ Department of Obstetrics and Gynecological Nursing, East Cost Hospital, Puducherry, India

Corresponding Author: Jaya Pradha Dhandapani, Department of Obstetrics and Gynecological Nursing, Kasturba Gandhi Nursing College, Sri Balaji Vidyapeeth (Deemed to be University), Puducherry, India, Phone: +91 7639126403, e-mail: J.pradhaa17@gmail.com

How to cite this article: Dhandapani JP, Ponnusamy V. Constriction Ring Syndrome. Pon J Nurs 2021;14(3):62-65.

Source of support: Nil

Conflict of interest: None

\section{Pathophysiology}

There is no clear etiology.

- The common assumption is that the interrupted amnion accidentally exposes the fibrous membranous strands that wrap the entire expanding $\operatorname{limb}^{7}$

\section{Degrees of Construction Ring Syndrome}

\begin{tabular}{ll}
\hline \multicolumn{1}{c}{ Degrees of CRS } \\
\hline $\begin{array}{l}\text { Simple constriction } \\
\text { rings }\end{array}$ & $\begin{array}{l}\text { Lymphedema or mild ring with no distal } \\
\text { deformity }\end{array}$ \\
$\begin{array}{l}\text { Rings with distal } \\
\text { deformity }\end{array}$ & $\begin{array}{l}\text { Ring may lead to distal lymphedema in } \\
\text { combination with deformity }\end{array}$ \\
Acrosyndactyly & $\begin{array}{l}\text { Skin is covered for most of the digits, but in a } \\
\text { proximal area, there is a distance between the } \\
\text { syndactyly with normal skin }\end{array}$ \\
& No limb distal to ring \\
\hline
\end{tabular}

(0) The Author(s). 2021 Open Access This article is distributed under the terms of the Creative Commons Attribution 4.0 International License (https://creativecommons [2]. org/licenses/by-nc/4.0/), which permits unrestricted use, distribution, and non-commercial reproduction in any medium, provided you give appropriate credit to the original author(s) and the source, provide a link to the Creative Commons license, and indicate if changes were made. The Creative Commons Public Domain Dedication waiver (http://creativecommons.org/publicdomain/zero/1.0/[3]) applies to the data made available in this article, unless otherwise stated. 


\section{Patterson Classification}

There are four categories as follows:

- Simple CRS ${ }^{9}$

- This syndrome with an abnormality of the fingers or toes may or may not occur in lymphedema

- This syndrome is more interrelated with terminal syndactyly or acrosyndactyly. ${ }^{9}$

- Amputation in the uterine ${ }^{9}$

Patterson I:There are simple constriction rings that are strands most likely around the distal extremities as toes and fingers. In common, the thumb is not damaged by a constriction ring because the fetus holds the thumb in tight adduction flexion, making entanglement with strands less common. ${ }^{10,11}$ These malformations need surgical removal, which must be carried out in different stages and can be done by various techniques. ${ }^{11}$

Patterson II: The CRS involves strands that occult the lymphatic vessels, thus leading to fluid retention, distal of the affected extremity. This interrupts itself with swollen parts distal of the constriction. ${ }^{11}$

Patterson III: This form has a complex form of syndactyly named acrosyndactyly, and the fingers (or toes) were primarily separated, but due to the constriction, they are developed back together. Sometimes, multiple fingers can interrupt. The distal binding between digits and toes never primarily conciliates a skeletal coalition. ${ }^{8}$ The digits are usually hypoplastic if multiple digits are interrupting. When the constriction obstructs the blood supply to the fingers, the fingers can form a peak with the most palmar digit being the index finger. Normal neurovascular bundles are absent in the parts of the distal. ${ }^{8}$ Hands with fused fingers need to be relived in phases to maintain the distal blood supply. ${ }^{11}$

Paterson IV: One of the most severe complications of constriction strains is probably intrauterine amputations; this is where the constriction leads as deep as the bone and occults the blood supply of the proximal extremity. ${ }^{8}$ The result is that the developing toe or finger will become ischemic and fall off. Due to the end analysis, transverse amputation occults the growing extremity of the vascular supply. ${ }^{12}$ The original syndrome is not seen, ${ }^{8}$ and this can lead to different endings.

- Complete resorption: This is the exemplary form of amputation. ${ }^{13}$ This way of the removal of the digit is entirely swallowing during intrauterine development, so the amputated digit is not visible

- Recovery of the digit: The fingers and toes are regained normal with the placenta during the time of delivery. ${ }^{15}$

- Engraftment elsewhere: In rare cases, the removal of the digit can be seen, and also, it grows together somewhere on the fetus. ${ }^{14}$

- Intrauterine death: In most minimal cases, a strain can develop all over the umbilical cord, and it can occult the blood supply to the fetus that leads to intrauterine death. ${ }^{15}$

\section{SignS AND Symptoms}

The constriction of attachment by amniotic bands may lead to:

- The syndrome that may appear all over the fingers or toes, arms, and legs

- Inflammation of both lower and upper extremities distal to the point of congenital lymphedema.
- Congenital amputation that may occur in arms, fingers or toes, and legs ${ }^{16}$

\section{DiAgnOSIS}

The diagnostic measures regarding the CRS can be authenticated with the help of ultrasonography. ${ }^{17}$ The clinical manifestations can be totally different, and also, it could be due to one or more manifestations. ${ }^{20}$ This can be validated at the end of the first trimester or at the beginning of the second trimester. ${ }^{21}$ But not all patients will be diagnosed at that time; many of them will get this diagnosis at birth. ${ }^{19}$

Individual strands are small in size and difficult to see on ultrasound, so bands are indirectly discovered as long as the constrictions enlarge the limbs or digits. ${ }^{18}$ Misdiagnosis is also common, so if there are any signs of amniotic bands, further detailed ultrasound tests should be done to assess the severity. ${ }^{22}$ Magnetic resonance imaging and 3D ultrasound can be utilized for more explanation and correct diagnosis of bands and the sequential damage or danger to the fetus. ${ }^{23}$

\section{TREATMENT}

Surgical correction is needed when a CRS leads to limb contour damage, with or without lymphedema. ${ }^{24}$

\section{Surgical Technique}

At the beginning of the surgery, a tourniquet will be applied to the limb. Tourniquets compress and control the arterial and venous circulation for about 2 hours. ${ }^{7}$ The constriction band must be dissected very carefully to avoid damaging the underlying neurovasculature. ${ }^{9}$ When the constriction band is excised, there will be a direct closure. This allows the fatty tissue to naturally reposition itself under the skin. ${ }^{25}$

"With complete circumferential constriction bands, it is recommended that a two-stage correction approach be used. At the first operation, one-half of the circumferences are excised and the other one-half can be excised after three to 6 months. This will avoid any problems to the distal circulation in the limb, which may already be compromised..$^{18}$ Lymphedema, when present, will significantly improve within a few weeks of the first surgery." ${ }^{26}$ For the direct closure of the defect after dissecting a constriction band, there are two different techniques:

- Triangular flaps: It is a modified technique. Here, triangular flaps can be introduced to one or the other of two proximal or distal to the ring depending upon the circumference of the limb in order to correct the deformity of the contour. ${ }^{27}$

- Z/W-plasty: It is one of the plastic surgery in order to develop the functional and cosmetic appearance of the scars. It can elongate a contracted scar or rotate the scar tension line. The middle line of the Z-shaped incision (the central element) is made along the line of greatest tension or contraction, and triangular flaps are raised on opposite sides of the two ends and then transposed. ${ }^{28}$

\section{Reconstructions and Prosthetics}

Treatment usually occurs after birth and where plastic and reconstructive surgery is considered to treat the resulting deformity. ${ }^{17}$ Plastic surgery ranges from simple to complex depending on the 
extent of the deformity. Physical and occupational therapy may be needed for the long term.

Prosthetics may help some ABS sufferers to live more functional lives. ${ }^{18}$ The price and complexity of these prosthetics vary dramatically, but advances in 3D printing have helped to increase the availability of artificial fingers while reducing their cost of production. ${ }^{5}$

\section{Prevention}

Amniotic band syndrome is considered an accidental event, and it does not appear to be genetic or hereditary, so the likelihood of it occurring in another pregnancy is remote. The cause of amnion tearing is unknown, and as such, there are no known preventative measures. $^{29}$

\section{Prognosis}

The prognosis depends on the location and severity of the constricting bands. ${ }^{30}$ Every case is different, and multiple bands may be entangled around the fetus. Bands that wrap around fingers and toes can result in syndactyly or amputations of the digits. ${ }^{30}$ In other instances, bands can wrap around the limbs causing restriction of movement, resulting in clubbed feet. ${ }^{30}$

\section{CONCLUSION}

Congenital CRS is of uncertain etiology and could cause morbidity in the newborn. The syndrome and its complications are amenable to corrective surgery with good results. Early intervention is desirable for a successful outcome. ${ }^{19}$ The incidence of CRS varies from one in $1500-15,000$ live births. There is no known racial predilection, and the male preponderance in this study is at variance with the equal sex characterized in other recounted. The incidence of familial is minimal, and it is described that there is no genetic susceptibility to this ailment. ${ }^{31}$

\section{References}

1. Higginbottom $M C$, Jones $\mathrm{KL}$, Hall $\mathrm{BD}$, et al. The amniotic band disruption complex: timing of amniotic rupture and variable spectra of consequent defects. J Pediatr 1979;95(4):544-549. DOI: 10.1016/ s0022-3476(79)80759-3.

2. Light TR, Ogden JA. Congenital constriction band syndrome. Pathophysiology and treatment. Yale J Biol Med 1993;66(3):143-155. Available at: https://pubmed.ncbi.nlm.nih.gov/8209551/.

3. Poeuf B, Samson P, Magalon G. Amniotic band syndrome. Chir Main 2008;27(Suppl 1):S136-S147. DOI: 10.1016/j.main.2008.07.016.

4. BurkCJ, Aber C, Connelly EA. Ehlers-Danlos syndrome type IV: keloidal plaques of the lower extremities, amniotic band limb deformity, and a new mutation. J Am Acad Dermatol 2007;56(2 Suppl):S53-S54. DOI: 10.1016/j.jaad.2006.11.008.

5. Patterson TJ. Congenital ring-constriction. Br J Plast Surg 1961;14:1-31. DOI: 10.1016/s0007-1226(61)80002-7.

6. Patterson TJ. Syndactyly and ring constrictions. Proc R Soc Med 1969;62(1):51-53. Available at: https://pubmed.ncbi.nlm.nih. gov/4303223/.

7. Streeter G. Focal deficiencies in fetal tissues and their relation to intrauterine amputations. Contrib Embryol 1930;22:1-44, DOI: December 05,2014,Vol- 4.No: 16

8. Moerman P, Fryns JP, Vandenberghe K, et al. Constrictive amniotic bands, amniotic adhesions, and limb-body wall complex: discrete disruption sequences with pathogenetic overlap. Am J Med Genet 1992;42(4):470-479. DOI: 10.1002/ajmg.1320420412.

9. Torpin R. Amniochorionic mesoblastic fibrous strings and amniotic bands: associated constricting fetal malformations or fetal death. Am J Obstet Gynecol 1965;91:65-75. DOI: 10.1016/0002-9378(65) 90588-0.

10. Robin NH, Franklin J, Prucka S, et al. Clefting, amniotic bands and polydactyl: a distinct phenotype that supports an intrinsic mechanism for amniotic band sequence. Am J Med Genet B Neuropsychiatry Genet Part A 2005;137A(3):298-301. DOI: 10.1002/ ajmg.a.30885.

11. Lateo SA, Taylor AE, Meggitt SJ. Raised limb bands developing in infancy. Br J Dermatol. 2006;154(4):791-792. DOI: 10.1111/j.13652133.2006.07160.x.

12. Werler MM, Louik C, Mitchell AA. Epidemiologic analysis of maternal factors and amniotic band defects. Birth Defects Res A Clin Mol Teratol 2003;67(1):68-72. DOI: 10.1002/bdra.10001.

13. Fathallah ZF. Unusual presentation of amniotic band syndrome. Bas J Surg 2007;11:77-79.

14. Jabor MA, Cronin ED. Bilateral cleft lip and palate and limb deformities: a presentation of amniotic band sequence? J Craniofac Surg 2000;11(4):388-393. DOI: 10.1097/00001665-20001104000021.

15. Evans C, Marton T, Rutter S, et al. Cranial vault defects: the description of three cases that illustrate a spectrum of anomalies. Pediatr Dev Pathol 2009;12(2):96-102. DOI: 10.2350/08-02-0415.1.

16. McGuirk CK, Westgate MN, Holmes LB. Limb deficiencies in newborn infants. Paediatrics 2001;108(4):e64-e70. DOI: 10.1542/peds. 108.4.e64.

17. Dilek TUK, Yazici G, Gulhan S, et al. Amniotic band syndrome associated with cranial defects and ectopiacordis: a report of two cases. J Turkish German Gynecol Assoc 2005;6(4):308-310.

18. Ogino T, Saitou Y. Congenital constriction band syndrome and transverse deficiency. J Hand Surg Br 1987;12:343-348. DOI: 10.1016/0266-7681(87)90185-9.

19. Garza A, Cordero JF, Mulinare J. Epidemiology of the early amnion rupture spectrum of defects. Am J Dis Child 1988;142:541-544. DOI: 10.1001/archpedi.1988.02150050079037.

20. Weinzweig N, Barr A. Radial, ulnar and median nerve palsies caused by a congenital constriction band of the arm: single stage correction. Plast Reconstr Surg 1994;94:872-876. DOI: 10.1097/00006534199411000-00022.

21. Allen LM. Constriction rings and congenital amputations of the fingers and toes in a mild case of amniotic band syndrome. JDMS 2007;23:280-285. DOI: September 1, 2007.

22. Merrimen JL, McNeely PD, Bendor-Samuel RL, et al. Congenital placental-cerebral adhesion: an unusual case of amniotic band sequence. Case report. J Neurosurgeon 2006;104(5 Suppl):352-355. DOI: 10.3171/ped.2006.104.5.352.

23. Rossillon D, Rombouts JJ, Verellen-Dumoulin C, et al. Congenital ring-constriction syndrome of the limbs: a report of 19 cases. Br J Plast Surg 1988;41:270-277. DOI: 10.1016/0007-1226(88)90111-7.

24. Upton J. Constriction ring syndrome. In: Mathes SJ, editor. Plastic surgery. The hand and upper limb, part 2. Vol. 8. 2nd ed. Philadelphia: Saunders Elsevier, 2006, pp. 185-213.

25. Kino Y. Clinical and experimental studies of the congenital constriction band syndrome, with an emphasis on its etiology. J Bone Joint Surg Am 1995; 57:636-643. Available at: https://pubmed.ncbi. nlm.nih.gov/1150705/.

26. De Pablo A, Calb I, Jaimovich L. Congenital constriction bands: amniotic band syndrome. J Am Acad Dermatol 1995;32:528-529. DOI: May 2014, ISSN NO 2277- 8179, issue :5, vol: 3.

27. Jobe MT, Wright PE. Congenital anomalies of hand: congenital ring syndrome. In: Terry Canale S, editor. Campbell's operative orthopaedics. 9th ed. St Louis: Mosby, 1999, p. 80. 
28. Gibson T. Pierre-Joseph Cecilien Simonart (1816-1846) and his intrauterine bands. Br J Plast Surg 1977;30:261-262. DOI: 10.1016/00071226(77)90112-6.

29. Pillay VK, Hesketh KT. Intra-uterine amputations and annular limb defects in Singapore. J Bone Joint Surg Br 1965;47:514. Available at: https://pubmed.ncbi.nlm.nih.gov/14341070/.
30. Moses JM, Flatt AE, Cooper RR. Annular constricting bands. J Bone Joint Surg Am 1979;61:562-565. Available at: https://pubmed.ncbi. nlm.nih.gov/374416/.

31. Hunter AG, Carpenter BF. Implications of malformations not due to amniotic bands in the amniotic band sequence. Is J Med Genet 1986;24:691. DOI: 10.1002/ajmg.1320240414. 